\title{
Acute Emamectin Benzoate Poisoning- A Fatal Case Report
}

\author{
Parth Godhiwala ${ }^{1}$, Apoorva Nirmal², Anand Bakre³ ${ }^{3}$ A. K. Wanjari ${ }^{4}$, Sunil Kumar ${ }^{5}$
}

\begin{abstract}
${ }^{1}$ Department of General Medicine, Jawahar Lal Nehru Medical College, Datta Meghe Institute of Medical Sciences (Deemed to be University), Wardha, Maharashtra, India. ${ }^{2}$ Department of General Medicine, Jawahar Lal Nehru Medical College, Datta Meghe Institute of Medical Sciences (Deemed to be University), Wardha, Maharashtra, India. ${ }^{3}$ Department of General Medicine, Jawahar Lal Nehru Medical College, Datta Meghe Institute of Medical Sciences (Deemed to be University), Wardha, Maharashtra, India. ${ }^{4}$ Department of General Medicine, Jawahar Lal Nehru Medical

College, Datta Meghe Institute of Medical Sciences (Deemed to be University), Wardha, Maharashtra, India.

${ }^{5}$ Department of General Medicine, Jawahar Lal Nehru Medical College, Datta Meghe Institute of Medical Sciences

(Deemed to be University), Wardha, Maharashtra, India.
\end{abstract}

\section{INTRODUCTION}

Emamectin benzoate is a broad-spectrum insecticide for vegetables having wide margin of safety as reported in animal studies, due to its low gamma-aminobutyric acid receptor affinities and very poor penetration to the blood-brain barrier. Not a single case has been reported about fatal human exposure in India. This case highlights about 40-year-old man who succumbed in intensive care unit even after all supportive treatment as well as with Flumazenil and Lipid emulsion. Emamectin benzoate is a semisynthetic avermectin, a class of natural fermentation products of Streptomyces avermitilis (soil microorganism). This is a broad-spectrum insecticide used for vegetables and are very popular now a days because of very low application rates, that means only small amount is needed to treat a large area (only $6 \mathrm{gm} /$ acre).[1] It acts by stimulating high-affinity gamma gamma-aminobutyric acid (GABA) receptors and a consequent increase in membrane chloride ion permeability and used as nematocidal, acaricidal and insecticidal.[1,2] on literature search only few studies are available regarding its toxic effects on humans and one case report describes rapid deterioration of a patient following its ingestion. ${ }^{[2]}$ Though specific antidote is not available for emamectin benzoate intoxication, this case highlights about 40 year old man who succumbed after acute suicidal poisoning with Emamectin Benzoate 5\% SG.

\section{PRESENTATION OF CASE}

A 40 years old farmer from rural village of Wardha district presented to the emergency department in our hospital with alleged history of consumption of Emamectin Benzoate 5\% SG, as a 500-gm container was found empty at the site of consumption by the relatives. Patient was a chronic alcoholic, and had consumed unknown amount of poison under the influence of alcohol due to financial debt. On asking from the relatives, there was no history of hypertension, diabetes mellitus, ischemic heart disease and any chronic respiratory illness. He was not on any medication. On examination patient was afebrile, drowsy and irritable having Glasgow Coma Scale (GCS) of E2V2M2. His blood pressure was 118/80 mmHg in right arm supine position; pulse rate was $128 / \mathrm{min}$, regular and respiratory rate was $26 / \mathrm{min}$. His both pupils were normal and reacting to light. On respiratory system examination he was having crackles in right infrascapular and lower axillary area. $\mathrm{He}$ was intubated and put on mechanical ventilator with CMV mode. Ryle's tube was put in and gastric lavage was given, which was odorless.
Corresponding Author:

Sunil Kumar,

Professor and HOD,

Department of General Medicine,

Jawahar Lal Nehru Medical College,

Datta Meghe Institute of Medical Sciences

(Deemed to be University),

Wardha, Maharashtra, India.

E-mail: sunilkumarmed@gmail.com

DOI: $10.14260 /$ jemds/2020/38

Financial or Other Competing Interests: None.

How to Cite This Article:

Godhiwala P, Nirmal A, Bakre A, et al. Acute emamectin benzoate poisoning-a fatal case report. J. Evolution Med. Dent. Sci. 2020;9(03):168-169,

$10.14260 / \mathrm{jemds} / 2020 / 38$

Submission 19-11-2019,

Peer Review 31-12-2019,

Acceptance 06-01-2020,

Published 20-01-2020.

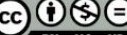


His laboratory reports were as follows: haemoglobin 10.2 $\mathrm{mg} / \mathrm{dL}$, Mean Corpuscular Volume 83, white blood cell counts 10400 per $\mathrm{mm}^{3}$, Total Platelets $101000 / \mathrm{mm}^{3}$. His kidney function test was within normal limits (blood Urea $28 \mathrm{mg} / \mathrm{dL}$; serum creatinine $0.6 \mathrm{mg} / \mathrm{dL}$; serum Sodium $139 \mathrm{meq} / \mathrm{l}$ and Potassium $4.2 \mathrm{meq} / \mathrm{l}$ ). His liver function revealed aspartate aminotransferase $48 \mathrm{U} / \mathrm{L}$, alanine aminotransferase $87 \mathrm{U} / \mathrm{L}$, Total Protein $8.6 \mathrm{mg} / \mathrm{l}$ with albumin $3.9 \mathrm{mg} / \mathrm{dL}$ and alkaline Phosphatase $93 \mathrm{U} / \mathrm{L}$. Lipid profile and coagulation profile were within normal limits. Ionic Calcium, magnesium and phosphorus were also normal. Serum ammonia level was 96 microgram/dL and random blood sugar was $124 \mathrm{mg} / \mathrm{dL}$. His acetyl cholinesterase level was also done thinking adulteration with organophosphorus pesticides, which was within normal limits. His chest radiograph showed heterogeneous infiltration in right lower lung suggestive of aspiration pneumonia. He was started with injectable ceftriaxone and metronidazole, and other supportive measures like intravenous fluids and diuretics for diuresis, as there is no antidote available of this insecticide.

On second day, patient developed myoclonic jerks with generalized seizure. At this time his blood sugar, serum electrolytes and arterial blood gas analysis were normal. Patient was put on injection Levetiracetam $500 \mathrm{mg}$ twice a day. His computerized tomography scan of brain and EEG was normal. As this insecticide acts on GABA, its receptor antagonist, flumazenil was started with the dose of $0.25 \mathrm{mg}$ IV over 15-30 sec, till maximum cumulative dose of $3 \mathrm{mg} / \mathrm{hr}$. Injectable lipid emulsion $20 \%$ was also started in the dose of $1.5 \mathrm{ml} / \mathrm{Kg}$ over 2 to 3 minutes as an IV bolus followed by an infusion of $0.25 \mathrm{ml} / \mathrm{Kg} / \mathrm{min}$. Patient had immediate response after flumazenil as he started localizing pain and cough reflex appeared. GCS became E3V4M4.

On $3^{\text {rd }}$ day patient developed severe metabolic acidosis and shock, so started with slow and low efficient haemodialysis under cover of intravenous norepinephrine. There was no improvement with this and after few hours he developed pulseless ventricular tachycardia. He succumbed even after aggressive resuscitative efforts because of cardiac arrest.

\section{DISCUSSION}

Emamectin benzoate is a broad-spectrum insecticide for vegetables having wide margin of safety as reported in animal studies. After accidental ingestion only mild clinical features had been reported such as mild disturbance of consciousness, gastrointestinal upset and aspiration pneumonia. Possible pathophysiology of this insecticide involves binding to high affinity GABA receptors and a consequent increase in membrane chloride permeability.[1,2] Wide margin of safety in mammals is because of GABA-mediated nerves occurring only in the central nervous system, whereas in many invertebrates such nerves regulate peripheral muscles.[2] Mammals are much less sensitive due to lower GABA receptor affinities and the relative partial crossing of the blood brain barrier.[2,3] In animal studies, there is evidence of high dose producing behavioural effects such as tremors and changes in motor activity (lethargy, hyperactivity, and/or ataxia), neuronal changes in the form of degeneration and vacuolation of the neuronal cytoplasm. The cytoplasmic vacuoles are associated with cellular debris, macrophages, and pyknotic nuclei.[4,5]

In our case, patient had presented in semiconscious state, sole manifestations of CNS affection. It was unclear whether the CNS manifestation resulted from the emamectin alone or in combination with alcohol or some other factors like solvent as adulteration. Emamectin benzoate has no specific antidote, so supportive and symptomatic should be started but as in our patient as there was good improvement during initial few days after injectable lipid emulsion therapy and flumazenil because of GABA receptor antagonist. More studies are required to prove this.

\section{CONCLUSIONS}

In spite of known non-lethality of emamectin benzoate, it can cause serious CNS manifestations and death. More studies are required regarding its pathogenesis and so treatment plan so that mortality can be prevented.

\section{REFERENCES}

[1] Yen TH, Lin JL. Acute poisoning with emamectin benzoate. J Toxicol Clin Toxicol 2004;42(5):657-61.

[2] Park JM. Rapid development of life-threatening emamectin benzoate poisoning. Emerg Med 2018;50(4):81-4.

[3] Kuo JN, Buday C, Van Aggelen G, et al. Acute toxicity of emamectin benzoate and its desmethyl metabolite to Eohaustorius estuarius. Environ Toxicol Chem 2010;29(8):1816-20.

[4] Armstrong R, MacPhee D, Katz T, et al. A field efficacy evaluation of emamectin benzoate for the control of sea lice on Atlantic salmon. Can Vet J 2000;41(8):607-12.

[5] Takai K, Suzuki T, Kawazu K. Development and preventive effect against pine wilt disease of a novel liquid formulation of emamectin benzoate. Pest Manage Sci 2003;59(3):365-70. 